\title{
A valsa nos trópicos: repercussões de um fenômeno europeu na literatura brasileira do século XIX
}

\section{Waltz in the Tropics: Repercussions of an European Phenomenon in Nineteenth Century Brazilian literature}

\author{
Claudia Helena Daher \\ Universidade Federal do Paraná, Curitiba, Paraná / Brasil \\ claudia.daher10@gmail.com
}

Resumo: Partindo de uma observação feita na obra Raízes do Brasil (1936), de Sérgio Buarque de Holanda, na qual o autor reflete sobre a disparidade entre a sociedade brasileira do século XIX e as ideias do liberalismo europeu, Roberto Schwarz desenvolve em Ao vencedor as batatas (1977) uma crítica ao Romantismo brasileiro, que teria sido montado sobre uma comédia ideológica, diferente da europeia, representando uma idealização que não correspondeu à realidade. $\mathrm{O}$ presente artigo revê esses conceitos a partir da cena de baile da obra Senhora (1875), de José de Alencar. Observa-se a presença da valsa na literatura brasileira oitocentista, objetivando analisar de que maneira esse fenômeno europeu se manifestou em território brasileiro e como $\mathrm{o}$ imaginário em torno do baile foi apropriado e relido pelo autor. $\mathrm{O}$ artigo coloca a literatura brasileira em diálogo com a literatura europeia produzida no mesmo período. Ao ponto de vista de Roberto Schwarz acrescenta-se o estudo feito por Maria Cecília de Moraes Pinto (1999) que investiga as influências europeias de Alencar e o seu empenho em fazer uma literatura nacional.

Palavras-chave: valsa na Europa e no Brasil; Romantismo; literatura nacional. 
Abstract: The piece of writing Raizes do Brasil (1936) by Sérgio Buarque de Holanda, in which the author reflects about the disparities between Brazilian society of the nineteenth century and the ideas of European liberalism, provides a basis to Roberto Schwarz's criticism of Brazilian Romanticism in Ao vencedor as batatas (1977). According to Schwarz, different from its European correlate, Brazilian Romanticism would have been based on an ideological comedy, thus representing an idealization that did not correspond to reality. This article revisits such concepts from the perspective of the ballroom dancing scene in Senhora (1875), by José de Alencar. Based on the presence of the waltz in nineteenth century Brazilian literature we analyzed how the European phenomenon manifested in Brazilian territory and how the imaginary constructed around ballroom dancing was appropriated and re-read by Alencar. This work establishes a connection between Brazilian Literature and the literature produced in Europe during the same period. In addition to Roberto Schwartz's point of view, we included Maria Cecília de Moraes Pinto's study (1999), which investigated Alencar's European influences and his efforts in creating a national literature.

Keywords: waltz in Europe and Brazil; Romanticism; national literature.

\section{Considerações iniciais: modelos europeus em terras brasileiras}

Em Ao vencedor as batatas (1977), Roberto Schwarz aponta o fato de que o Brasil do século XIX estava muito aquém da realidade europeia no que diz respeito à ciência econômica e às ideologias políticas. Endossando o seu ponto de vista, ele menciona que diversos autores refletem sobre a "disparidade entre a sociedade brasileira, escravista, e as idéias do liberalismo europeu" (SCHWARZ, 2000, p. 12).

Dentre esses autores, Roberto Schwarz cita Sérgio Buarque de Holanda, mais precisamente, a obra Raizes do Brasil (1936): "Trazendo de países distantes nossas formas de vida, nossas instituições e nossa visão do mundo e timbrando em manter tudo isso em ambiente muitas vezes desfavorável e hostil, somos uns desterrados em nossa terra" (HOLANDA, 1956, p. 15, apud SCHWARZ, 2000, p. 13).

Assim, partindo da premissa de que as ideias que gravitavam no contexto brasileiro do século XIX estavam "fora do lugar", Roberto Schwarz (2000, p. 10) analisa a recepção dos modelos europeus na 
literatura brasileira daquele período, apontando o desequilíbrio e as falhas que a transposição de um modelo europeu sofreu ao tentar ser adaptado pelos escritores brasileiros. Segundo a sua observação, no Brasil as ideias estavam fora de centro, em relação ao seu uso europeu. O nosso contexto era diferente, embora usássemos os mesmos termos e fingíssemos uma realidade que não existia. A incoerência entre o plano ideológico e a vida prática fica evidente quando Schwarz nos lembra algumas das tentativas de europeização da sociedade brasileira:

Sobre as paredes de terra, erguidas por escravos, pregavam-se papéis decorativos europeus ou aplicavam-se pinturas, de forma a criar a ilusão de um ambiente novo, como os interiores das residências dos países em industrialização. (SCHWARZ, 2000, p. 22).

Da mesma forma como as casas eram decoradas a fim de ficarem parecidas com ambientes europeus, a sociedade tentava encobrir com finas estampas a realidade daquele sistema baseado na exploração do trabalho escravo.

Em consequência, os autores da época tentavam importar um imaginário literário da Europa e adaptá-lo ao contexto da sociedade brasileira, mas segundo Schwarz (2000) esta transposição não foi bemsucedida. Grande parte da literatura brasileira do século XIX seria, portanto, uma tentativa frustrada de seguir os modelos europeus dentro de uma sociedade que apresentava um contexto bastante diferente. Escolhendo como exemplo de análise a obra Senhora (1875), de José de Alencar, Schwarz (2000) denuncia as falhas e adaptações forçadas desta imitação, apontando o que para ele seria um desacordo entre a representação e o seu contexto. A literatura de Alencar representaria as feições da sociedade fluminense que copiava a europeia, e isso dentro de um modelo literário igualmente copiado da Europa. No entanto, para Schwarz (2000), os problemas vivenciados pela sociedade europeia não eram os mesmos brasileiros e, portanto, a obra de Alencar apresentaria uma disjunção entre forma e conteúdo. Alencar inspira-se em Balzac, mas, preso ao estilo europeu, não consegue captar as nuances da sociedade brasileira como tão bem o fizera seu condiscípulo francês. Assim, para Schwarz, se a intriga principal pode ser considerada bem construída, ela não representa realmente as cores locais brasileiras: poder-se-ia 
transpor a história de Aurélia e de Seixas para um contexto europeu e ela continuaria a mesma.

Partindo dessas observações feitas por Schwarz (2000), propomonos neste artigo a analisar uma cena em específico da obra Senhora: a cena de baile.

\section{0 baile em Senhora, de José de Alencar: a sedução e o escândalo da valsa}

Retomando a obra Senhora, lembremos que as quatro partes que constituem o romance - "O preço", "Quitação", "Posse" e "Resgate" ressaltam o aspecto pecuniário que move a atitude dos personagens e sela um casamento de conveniências. Fernando Seixas é moralmente um personagem sem grandeza, que gasta o que não tem para ostentar uma bela aparência e conseguir um "bom casamento". Essa mediocridade só se redime ao influxo da ação pedagógica de Aurélia Camargo. Pode-se dizer que à deseducação da sociedade Aurélia contrapõe a educação pelo amor: o texto ressalta que o amor pode salvar as pessoas da despersonalização capitalista.

Os bailes permeiam o romance desde o início. Após receber sua fortuna, é nos bailes da sociedade fluminense que Aurélia faz sua aparição fulgurante, tornando-se a rainha dos salões: "Tornou-se a deusa dos bailes; a musa dos poetas e o ídolo dos noivos em disponibilidade" (ALENCAR, 1997, p. 14). O baile é a maneira existente para se exibir à sociedade, pois trata-se de um momento privilegiado de encontro e de exposição, como uma vitrine. Os bailes funcionam, ao menos no plano do imaginário, como um lugar propiciador de futuros casamentos, como podemos observar, aliás, em outras cenas da literatura. Depois de casada, Aurélia também vai aos bailes para mostrar à sociedade que é feliz com o casamento, o que não é verdade. Ela apenas finge que se diverte: "Quero que o mundo me julgue feliz" (ALENCAR, 1997, p. 132). A cena de baile na qual concentrar-nos-emos neste trabalho representa "um preâmbulo estéticoerótico à decisiva aproximação de Aurélia e Fernando", nas palavras de Maria Cecília Queiroz de Moraes Pinto (1999, p. 187); cena durante a qual, depois de algum tempo de casados e não tendo tido nenhum tipo de aproximação, os protagonistas dançam uma valsa, prenunciando um possível entendimento. 
A cena ressalta, ademais, a ilusão que permeia o mundo social que acredita nas aparências de uma vida conjugal feliz entre Aurélia e Fernando quando ela é na verdade inexistente. O intuito mesmo da recepção, oferecida por Aurélia na sua própria casa, é o de mostrar à sociedade o quanto o seu casamento com Fernando Seixas é bemsucedido. Toda a cena converge em direção a uma falácia, pois nada do que Aurélia apresenta é verdadeiro, nem o seu casamento nem a sua pretensa felicidade.

É no diálogo repleto de provocações que se estabelece entre Aurélia e Fernando, logo no início da cena de baile, que se trava uma discussão sobre a palavra que dá título à obra. Fernando pronuncia a palavra à brasileira, com o $o$ aberto, e explica:

[Senhôra] é, creio eu, a verdadeira pronúncia da palavra; mas nós, os brasileiros, para distinguir da fórmula cortês, a relação de império e domínio, usamos da variante que soa mais forte, e com certa vibração metálica. O súdito diz à soberana, como o servo à sua dona, senhóra. Eu talvez não reflita e confunda. (ALENCAR, 1997, p. 143, grifos nossos).

O trecho exemplifica a relação entre os dois protagonistas. Embora estejam casados, Fernando é uma "posse" de sua esposa, e este sentimento de subalternidade transparece no pronome de tratamento que ele utiliza, que denota não uma cortesia, mas um assujeitamento.

Compreendendo a relação entre os personagens, cuja união ainda não fora consumada, e a posição de "súdito" assumida por Fernando, podemos avaliar a importância desta cena de baile dentro da intriga. Em nenhum outro momento da narrativa descreve-se um encontro de intimidade entre os personagens tão intenso como este, que tem lugar durante a valsa. $\mathrm{O}$ encontro dos corpos, a vibração da música, a velocidade com que giram e a forte emoção que arrebata Aurélia no final: trata-se, a nosso ver, da cena mais ousada do romance. A cena oferece ao leitor muito mais detalhes e intensidade dramática do que a própria noite de núpcias, que acontece no final do romance e que se resume a uma frase. A forte impregnação sexual da cena não escapou, aliás, à análise da crítica, como sustenta Pinto (1999, p. 188).

Como vimos, a cena não é apenas ousada pelo seu caráter sensual latente, mas por apresentar uma situação social do século XIX de maneira invertida, pois quem deveria submeter-se às vontades do 
marido era habitualmente a mulher. No caso, os dois só dançam porque os convidados, incitados por Lísia Soares, amiga de Aurélia que quer provocá-la, insistem em ver o casal valsando. Aurélia, sentindo-se desafiada, concede ao pedido. Fernando chega a desincumbi-la de tal ação, dizendo que ele pode declinar, se ela assim o preferir, mas Aurélia decide manter o desafio. Vê-se que ainda aí quem está no comando é a mulher. $\mathrm{O}$ que se espera de um baile deste período é que a tomada de atitude venha do homem: é ele quem convida a dama para dançar. Nesta cena, ao contrário, o homem cede, ele apenas obedece aos caprichos de sua mulher. Alencar brinca com as conveniências e, desta maneira, denuncia e critica costumes morais de sua época. O que impressiona neste livro é justamente o fato de que aquele que é "comercializado" é um homem, o que vai de encontro aos costumes sociais da época.

A cena coloca em evidência a emoção experimentada por ambos através do contato físico: "era a primeira vez que o braço de Seixas enlaçava a cintura de Aurélia. Explica-se, pois, o estremecimento que ambos sofreram ao mútuo contato, quando essa cadeia viva os prendeu" (ALENCAR, 1997, p. 147). Aurélia dança com "silfidez e graça" (ALENCAR, 1997, p. 147), provocando ciúmes nas outras convidadas. $\mathrm{O}$ aspecto da sedução oriunda da dança é igualmente ressaltado:

[ela] tinha no seu [semblante] uma sedução irresistível e uma beleza fatal e deslumbrante.

Nunca se fixou na tela, nem se lavrou no mármore, tão sublime imagem da tentação, como aí estava encarnada na altivez fascinante da formosa mulher. (ALENCAR, 1997, p. 147, grifos nossos).

Desde que a valsa é mencionada no texto, ela vem acompanhada de uma caracterização depreciativa:

Desde a primeira vez que apareceu na sociedade, depois do luto de sua mãe, Aurélia que apesar da palavra afoita e viva, tinha o casto recato de sua pessoa, resolveu não valsar para não arriscar-se a encontrar um desses pares que põe ao vivo a comparação poética da trepadeira enroscada ao musgoso. (ALENCAR, 1997, p. 146).

Observa-se que a valsa é descrita de maneira a colocar em evidência a excessiva aproximação dos corpos. Logo na sequência, o narrador faz uma digressão para explicar o "perigo" que representava 
a valsa em terras brasileiras. Ele lembra que a valsa se originou na Alemanha e sugere que talvez nesse país a dança não tenha um efeito tão nocivo: é possível que com o clima frio, a valsa seja uma dança "decente". Mas, ao chegar ao hemisfério sul, a valsa se torna escandalosa e deveria, segundo o narrador, ser executada apenas nos bailes públicos e não nos salões de família. Ele evoca que esta dança impetuosa já havia sido alvo de críticas do escritor Victor Hugo:

Há nessa dança impetuosa alguma coisa que lembra os mistérios consagrados a Vênus pela Grécia pagã, ou o delírio das bacantes quando agitavam o tirso. "É, na frase do grande poeta, a valsa impura e lasciva, desfolhando as mulheres e as flores".

Nunca a linguagem, que esse rei da palavra, chamado Victor Hugo, subjuga e maneja como um brioso corcel, prestou-se à mais eloqüente expressão do pensamento. É realmente a desfolha da mulher, a despolpa de sua beleza e de sua pessoa, o que a valsa impudica faz no meio da sala, em plena luz, aos olhos da turba ávida e curiosa.

As senhoras não gostam da valsa, senão pelo prazer de sentirem-se arrebatadas no turbilhão. Há uma delícia, uma voluptuosidade pura e inocente, nessa embriaguez da velocidade. Aos volteios rápidos, a mulher sente nascer-lhe as asas, e pensa que voa; rompe-se o casulo de seda, desfralda-se a borboleta.

Mas é justamente aí que está o perigo. Esse enlevo inocente da dança, entrega a mulher palpitante, inebriada, às tentações do cavalheiro, delicado embora, mas homem, que ela sem querer está provocando com o casto requebro de seu talhe e traspassando com as tépidas emanações de seu corpo. (ALENCAR, 1997, p. 148-149).

Observando o surgimento da valsa, não foi ao chegar ao Brasil que esta dança se tornou escandalosa, ela já era considerada ousada mesmo nos países europeus, conforme sustenta Hess na obra La valse: révolution du couple en Europe (1989). Ao dizer que a valsa motiva a "desfolha da mulher" e que, dançando-a, "rompe-se o casulo de seda, desfralda-se a borboleta", o narrador ressalta o aspecto libertador da dança e, por conseguinte, do próprio baile enquanto um lugar de metamorfose e de transformação. A metáfora da borboleta que alça voo remete-nos à jovem que passa de um estado de pureza e inocência à descoberta dos primeiros impulsos e desejos sexuais. 
O narrador remete-nos a um texto de Victor Hugo. Trata-se do vigésimo terceiro poema publicado na coletânea Les feuilles d'automne (1831): uma composição de um único período, no qual várias orações condicionais iniciadas pela conjunção "se" levam à oração principal. $\mathrm{O}$ eu lírico descreve a valsa com desconfiança e mesmo com raiva, como alguém que observa o ser amado dançando com outro e se sente enciumado:

Si vous n'avez jamais vu d'un œil de colère

La valse impure, au vol lascif et circulaire,

Effeuiller en courant les femmes et les fleurs;

$[\ldots]$

Vous n'avez point aimé, vous n'avez point souffert!1

(HUGO, 1837, p. 503, grifos nossos)

Um aspecto observado por Maria Cecília Queiroz de Moraes Pinto (1999, p. 188) é que na transcrição em prosa perde-se a imagem do rodopio "au vol lascive et circulaire" sugestionado pelo poema de Victor Hugo. A imagem será recuperada, contudo, no desenrolar da cena, na descrição de movimentos e sensações do par de valsistas, como destacamos no trecho a seguir:

Aurélia tinha nessa noite um vestido de tule cor de ouro, que a vestia como uma gaze de luz. Com o voltear da valsa, as ondas vaporosas da saia e a manga roçagante do braço que erguera para apoiar-se em seu par, flutuavam como nuvens diáfanas embebidas de sol, e envolviam a ela e ao cavalheiro como um brilhante arrebol. Parecia que voavam ambos arrebatados ao céu por uma assunção radiosa. (ALENCAR, 1997, p. 147, grifos nossos).

O encanto que envolve o "airoso par" que se balança "à cadência da música arrebatadora" contribui para que ambos se deixem conduzir em direção a uma "sedução irresistível". Além disso, a presença da metáfora "a valsa [...] desfolhando as mulheres e as flores", usada por Alencar, conserva a essência do pensamento hugoano, como demonstrado por Pinto:

\footnotetext{
${ }^{1}$ Se você nunca viu com um olhar de cólera/ A valsa impura, de voo lascivo e circular,/ Desfolhar rapidamente as mulheres e as flores;/ [...]/ Você jamais amou, você jamais sofreu! (Tradução livre).
} 
Entre a desfolha e a referência às folhas, insinua-se a defloração da mulher, prenúncio do que será a mútua entrega das personagens à volúpia dos sentidos e o fim de um casamento branco. Assim, todo o final do capítulo acaba por ilustrar a citação, dilatando-a em sinuosa hipérbole de que se percebem os ecos no último lance da última página do romance, ou seja, no feliz desfecho. (PINTO, 1999, p. 188).

A cena de baile em Senhora evolui num crescendo, no qual os dançarinos dançam cada vez mais rapidamente, numa descrição que nos remete à valsa experimentada por Emma Bovary, na obra Madame Bovary (1857), de Gustave Flaubert, quando tudo parece rodar em torno dos dançarinos. Aurélia insiste em dançar rapidamente, garantindo que assim não sentirá tonturas: “- Em tudo sou esquisita! - Devagar é que tonteio. - A casa roda em torno de mim. - Depressa não. Quando tudo desaparece... - Quando não vejo mais nada... - Então sim! - Então gosto de valsar!" (ALENCAR, 1997, p. 148).

Vulneráveis pelo contato físico tão próximo, os personagens terminam por se beijar. Um leve roçar de lábios, mas que faz com que Aurélia, tomada pela emoção, desmaie nos braços de Seixas. O desmaio de uma moça depois de uma forte emoção não é uma cena rara na literatura deste período. No entanto, mais do que um lugar-comum literário, o desmaio de Aurélia exemplifica o imaginário sobre os malefícios da dança, que foi alimentado pelos defensores da moral e dos bons costumes. Houve, de fato, muitas críticas às danças no século XIX, a começar pela Europa, onde surgiram muitas danças que se popularizaram pelos salões, como a valsa e a polca. As danças eram consideradas escandalosas demais e, nesse sentido, Montandon (2000, p. 18) afirma que mesmo a medicina se manifestou em defesa dos princípios morais, denunciando o perigo da valsa e da polca para a saúde das mulheres. Dizia a medicina da época que, ao dançar, uma moça resplandecente de saúde poderia apanhar tuberculose, cair de fadiga, ser vítima de um prolapso do útero ou mesmo vir a morrer repentinamente. Observa-se, contudo, que as críticas às danças eram mais de caráter moral do que físico. $\mathrm{O}$ perigo da dança estava sobretudo no que ela poderia fazer à sensibilidade das jovens do que propriamente ao seu organismo. 


\section{O topos do baile e o esforço de construção de uma literatura na- cional}

As cenas de baile haviam, com efeito, se tornado frequentes na literatura europeia do século XIX. Refletindo um fenômeno de liberação social e individual, Alain Montandon (2000) observa que os bailes configuram um topos literário na literatura francesa que pode ser observado em diversos autores, de Stendhal a Balzac, de Flaubert a Émile Zola. Na literatura portuguesa os bailes também fizeram sua aparição. A título de exemplo, podemos citar três cenas nas quais o baile assume uma importância para o desenvolvimento do enredo: a que inicia Anos de prosa (1863), de Camilo Castelo Branco, momento de encontro dos protagonistas (cf. CASTELO BRANCO, 1973); aquela de Os canibais (1868), em que Álvaro do Carvalhal ironiza o imaginário literário e social de uma festa aristocrática e elegante, tradicionalmente associado ao baile (cf. CARVALHAL, 2004); e um terceiro exemplo pode ser encontrado na obra A capital (1925, obra póstuma), de Eça de Queirós, em momento em que o autor coloca em evidência temas que revelam as torpezas humanas e sociais, exaltando o comportamento bruto e quase animalesco do ser humano (cf. QUEIROZ, 1997).

A temática do baile estava, portanto, em voga na Europa. Por essa razão, retomando a afirmação de Roberto Schwarz (2000, p. 12) de que no Brasil as ideias estavam fora de contexto e de que a obra Senhora seria apenas um simulacro de uma situação europeia, poderíamos nos questionar: se as representações de baile na Europa do século XIX já podem ser consideradas uma ilusão de um mundo inexistente, visto que remetem a um tempo de riqueza e fartura atrelado ao imaginário tradicional do baile da corte (ilustrado pelo conto de Cinderela de Charles Perrault), seria no Brasil uma "ilusão" ainda maior, visto que é a imitação de uma prática europeia, não compatível com a nossa realidade? Observando atentamente, no entanto, vemos que a disjunção estava posta naquela sociedade. Alencar descreveu o que era a própria sociedade: as pessoas abastadas se comportavam como se estivessem na Europa. Não acreditamos que aqui o contexto seja mais ilusório, pois as pessoas viviam aquilo como "real". Não apenas na literatura: sabemos que a inspiração europeia guiava os paradigmas artísticos, arquitetônicos, de vestuário e de comportamento. Os bailes, neste sentido, exemplificam este elo com a Europa mantido pelas classes superiores no Brasil, ou 
seja, os bailes não aparecem apenas na literatura, eles faziam parte dos rituais apreciados pela sociedade.

Muito se tem discutido sobre a localização de Alencar no centro das polêmicas que, durante todo o Romantismo e mesmo muito depois, centraram-se na questão da nacionalidade da literatura brasileira. Neste sentido, a pesquisa realizada por Maria Cecília Queiroz de Moraes Pinto (1999) nos fornece um trabalho comparativo sobre as influências francesas na obra de Alencar, mostrando que o autor utiliza todo o cabedal de conhecimento das literaturas estrangeiras não para copiá-las, mas para construir aquilo que ele entende como um projeto de literatura nacional. A reivindicação de nacionalidade ocorre pela presença de imagens e paradigmas que transparecem na organização dos próprios sintagmas narrativos. A autora mostra que justamente nas obras de caráter urbano, nas quais o escritor poderia parecer (como foi, de fato, lido por uma grande parte da crítica) mais afastado do seu projeto de uma literatura nacional, é onde mais se pode notar o esforço em instaurar uma literatura brasileira que pudesse acertar seus passos com relação ao que se fazia nos centros irradiadores de cultura.

Neste sentido, a própria evocação a Victor Hugo, durante a cena de baile, pode ser vista não como uma simples cópia, mas como uma releitura. $\mathrm{O}$ escritor brasileiro capta para a sua narrativa uma expressão cujo valor será invertido. Na valsa de Aurélia e Fernando não temos um olhar externo de suspeita e de ciúme (un oeil de colère) como é o caso do eu lírico hugoano, mas a revelação do amor. A sensualidade da valsa contribui aqui para que os personagens percebam que se amam.

Além disso, a descrição da valsa permite ainda um olhar sobre a conjuntura social carioca e o que se esperava em relação ao comportamento de um casal. Ora, o perigo moral que o narrador vê nas valsas dançadas no Brasil não se aplica ao casal Aurélia e Fernando Seixas, pois é compensada pelo fato tranquilizador de serem eles oficialmente casados, apesar da equívoca situação em que vivem. Alencar deixa bem clara essa observação ao escrever: "O que é a valsa, mostrava-o aquele formoso par que girava na sala; e ao qual entretanto defendia dos olhos maliciosos a casta e santa auréola da graça conjugal, com que Deus os abençoara" (1997, p. 149).

Para Tinhorão (2000, p. 153) essa observação de Alencar coloca em evidência o supremo grau da hipocrisia da moral oficial brasileira do século XIX, ainda impregnada das tradições patriarcais baseadas 
no poder das convenções contratuais. Não importava que o casamento de Aurélia e Seixas fosse uma farsa para os dois: o importante é que qualquer atitude de ambos, capaz de ser julgada socialmente atrevida ou imoral em um par não casado, ficava neles justificada pela presença de um documento legal. A graça de Deus servia inclusive para sancionar as situações hipócritas.

\section{Considerações finais: o baile, fenômeno europeu, em uma releitura brasileira}

O próprio Alencar havia se defendido, como pode-se observar no prefácio da obra Sonhos d'ouro (1872), daquilo que os críticos poderiam achar uma europeização em sua literatura. Onde Schwarz (2000) vê um defeito de composição, Alencar via um acerto da imitação. No prefácio de Sonhos d'ouro (1872), Alencar escreve:

Tachar êstes livros de confeição estrangeira é, relevem os críticos, não conhecer a fisionomia da sociedade fluminense, que aí está a faceirar-se pelas salas e ruas com atavios parisienses, falando a algemia universal, que é a língua do progresso, jargão erriçado de têrmos franceses, inglêses, italianos, e agora também alemães.

Como se há de tirar a fotografia desta sociedade, sem lhe copiar as feições? (ALENCAR, [s.d.], p. 11).

As informações paratextuais deixadas por Alencar nos prefácios, posfácios, registros de autoria, de gênero, notas, dedicatórias e mesmo a apresentação gráfica contêm efetivamente verdadeiras instruções de leitura. Pinto (1999, p. 36) aponta igualmente no prefácio de Sonhos d'ouro um exemplo claro dos objetivos do romancista. Neste texto, Alencar trata de alguns pontos que vislumbram o momento cultural do Brasil e, nele, a situação da literatura emergente. A autora assinala que "para além de uma ordenação da própria obra, Alencar avança concepções críticas e de história literária, baseadas em valores e vivência brasileiros" (PINTO, 1999, p. 39). Em outras palavras, Alencar tem consciência e conhecimento do mundo que estava representando em suas obras.

Enfim, mesmo Schwarz, que aponta o que considera os desajustes da obra de Alencar, declara que o romance não deixa de ser ousado pelo tema: 
Considere-se o que significava, como atualização e desenvoltura, fazer que uma personagem, mulher ainda por luxo, tratasse livremente das questões de que então, ou pouco antes, tratara o Realismo europeu. Em certo sentido muito claro, é um feito, seja qual for o resultado literário. (SCHWARZ, 2000, p. 45).

Schwarz também reforça que a fórmula básica do romance deste período - seja na literatura europeia, seja na brasileira - é a contradição dos ideais dos personagens com o capitalismo vigente na sociedade moderna, o que sempre termina com uma desilusão. Alencar "coloca no centro do romance a coisificação burguesa das relações sociais" (SCHWARZ, 2000, p. 79), o que não deixa de apresentar uma audácia e uma complexidade consideráveis.

De fato, pode-se observar que nas entrelinhas de Senhora afloram as críticas ao capitalismo nascente, à coisificação das relações humanas, à condição da mulher. Neste sentido, Pinto observa que apesar de suas estreitas relações com escritores franceses, Alencar destoa, por exemplo, de Balzac. O romancista brasileiro parece ser mais otimista: Alencar vê e propõe saídas: "Nas soluções individuais da ficção, repercute a consciência de sermos um país novo que deverá evitar os erros do Velho Mundo" (PINTO, 1999, p. 197). Sem dúvida, à luz da nossa contemporaneidade, parece impróprio que Alencar tenha dito que devemos evitar os erros da exploração capitalista europeia em uma sociedade ainda escravocrata. No entanto, ao criticar o que se passa no estrangeiro, Alencar de certa forma evidencia a nossa própria miséria.

Fingimento, espetáculo, autenticidade e conveniência, conflito entre ser e parecer são elementos que transparecem neste texto e, sobretudo, nesta cena de baile. A escrita de Alencar aproveita a lição de outras culturas, mas procura o próprio caminho, a própria medida. À semelhança de outros personagens estrangeiros, Seixas passa por uma reeducação e aprende, no final, a ser um homem digno de amar e ser amado. Mas há, durante toda a obra, uma tentativa de colocar esse personagem no âmbito nacional. Senhora marca a tensão da palavra que se quer brasileira e a pressão não só da cultura estrangeira como também de todo o sistema político, econômico, social a que seria difícil escapar. $\mathrm{O}$ baile, enfim, festa que nasceu no seio da Europa, durante a Idade Média, aparece neste contexto relida por um brasileiro, em uma representativa cena das atividades realizadas pela burguesia brasileira do século XIX. 


\section{Referências}

ALENCAR, J. de. Senhora. São Paulo: O Estado de São Paulo; Klick Editora, 1997.

ALENCAR, J. de. Sonhos d'ouro. 8. ed. Ilustrações de Pedro Riu. São Paulo: Melhoramentos, [s.d.].

CARVALHAL, Á. do. Os canibais. Coimbra: Alma Azul, 2004.

CASTELO BRANCO, C. Anos de prosa. 4. ed., conforme a 2. ed., revista pelo autor. Lisboa: Parceria A. M. Pereira, 1973.

HESS, R. La valse: révolution du couple en Europe. Paris: A. M. Métailié, 1989.

HOLANDA, S. B. de. Raízes do Brasil. Rio de Janeiro: José Olympio, 1956 apud SCHWARZ, R. Ao vencedor as batatas: forma literária e processo social nos inícios do romance brasileiro. 5. ed. São Paulo: Duas Cidades/Editora 34, 2000.

HUGO, V. Les feuilles d'automne: vingt-troisième. In: . Euvres. Bruxelles: Meline, Cans et Compagnie, 1837. v. 2. p. 503.

MONTANDON, A. (Org.). Paris au bal: treize physiologies sur la danse. Paris: H. Champion, 2000.

PINTO, M. C. Q. de M. Alencar e a França: perfis. São Paulo: Annablume, 1999.

QUEIROZ, E. de. A Capital! In: . Obra completa. Organização geral, introdução, fixação dos textos autógrafos e notas introdutórias de Beatriz Berrini. Rio de Janeiro: Nova Aguilar, 1997. v. II. p.649-929.

SCHWARZ, R. Ao vencedor as batatas: forma literária e processo social nos inícios do romance brasileiro. 5. ed. São Paulo: Duas Cidades/Editora 34, 2000.

TINHORÃO, J. R. A música popular no romance brasileiro: séculos XVIII e XIX. São Paulo: Editora 34, 2000. v. 1.

Recebido em: 30 de abril de 2017. Aprovado em: 2 de outubro de 2017. 